\title{
Vivências de pessoas LGBT em situação de rua e as relações com a atenção e o cuidado em saúde em Florianópolis, $\mathrm{SC}$
}

\author{
Experiences of LGBT homeless people and its relations with health \\ care in Florianopolis, $S C$
}

Dalvan Antonio de Campos ${ }^{\mathbf{1}}$, Heitor Mondardo Cardoso ${ }^{\mathbf{1}}$, Rodrigo Otávio Moretti-Pires ${ }^{\mathbf{1}}$

DOI: $10.1590 / 0103-110420195806$

RESUMO As identidades de gênero e as orientações sexuais têm impacto sobre as vivências das pessoas em situação de rua, sendo importante motivo na quebra de vínculo familiar e ida para a rua, no caso, Lésbicas, Gays, Bissexuais, Travestis e Transexuais (LGBT). LGBT em situação de rua têm sua relação com o serviço de saúde comprometida e apresentam os piores indicadores de saúde quando comparados com os heterossexuais. O objetivo deste estudo foi compreender as implicações das identidades de gênero nas relações sociais e saúde de LGBT em situação de rua de Florianópolis (SC). Trata-se de uma pesquisa qualitativa realizada entre os meses de novembro de 2017 e fevereiro de 2018, com LGBT em situação de rua, no centro de Florianópolis (SC). Foram realizadas entrevistas individuais semiestruturadas para coleta de dados. Os principais motivos de ida para a rua foram os conflitos familiares e a opção pessoal. A rua foi apresentada como um espaço de intensa discriminação e violência contra LGBT, com aspectos interseccionais relacionados com a raça, amenizadas por estratégias de 'desvio de foco'. Devido às experiências discriminatórias com profissionais de saúde, o cuidado de saúde é feito pelas próprias pessoas em situação de rua.

PALAVRAS-CHAVE Pessoas em situação de rua. Minorias sexuais e de gênero. Assistência integral à saúde. Discriminação social.

ABSTRACT Gender identities and sexual orientation have an impact on the lives of homeless people, and are an important reason for breaking the family bond and ending up in the streets, in the case of Lesbians, Gays, Bisexuals, Transvestites and Transsexuals (LGBT). LGBT homeless people have their relationship with the health service compromised and have the worst health indicators when compared to heterosexuals. The aim of this study was to understand the implications of gender identities in social relations and health of the LGBT homeless population in Florianópolis (SC). It is a qualitative research carried out between November 2017 and February 2018, with LGBT homeless people in the city center of Florianópolis (SC). Individual semi-structured interviews were conducted for data collection. The main reasons for going to the street were family conflicts and personal choice. The street was presented as a space of intense violence and discrimination against LGBT population with intersectional aspects related to race, enlivened by some strategies of 'shifting of focus'. Due to discriminatory experiences with health professionals, health care is carried out by the very people in homeless situation.

1 Universidade Federal de Santa Catarina (UFSC) Florianópolis (SC), Brasil. dalvandecampos@gmail. com
KEYWORDS Homeless person. Sexual and gender minorities. Comprehensive health care. Social discrimination. 


\section{Introdução}

O Movimento da Reforma Sanitária, ao questionar o status quo vigente e apontar as mudanças e transformações necessárias na sociedade e na saúde, foi fundamental para a introdução do direito universal à saúde no texto constitucional e criação do Sistema Único de Saúde (SUS) $\mathbf{1}$. Apesar da implementação de diversos programas e políticas públicas de saúde desde a criação do SUS, alguns grupos sociais continuam mais vulneráveis e vulnerados devido a questões econômicas e socioculturais. A discriminação racial, de gênero e por orientação sexual são fatores que dificultam o acesso aos serviços de saúde de pessoas em Situação de Rua² e de Lésbicas, Gays, Bissexuais, Transexuais e Travestis (LGBT) ${ }^{3}$.

A População em Situação de Rua (PSR) é identificada como um grupo social heterogêneo, caracterizado pela pobreza extrema, vínculos familiares interrompidos ou fragilizados e inexistência de moradia convencional regular, utilizando as ruas e espaços públicos como seu local de relações sociais, moradia e sustento ${ }^{2}$. Parte dessa população é constituída por LGBT, grupo que apresenta especificidades em relação às experiências de discriminação e necessidades de saúde ${ }^{4,5}$.

Percebeu-se um crescimento da PSR no Brasil entre os anos de 2008 e 2016, passando de aproximadamente 50 mil6 para $101.854^{7}$. Essa tendência também é observada em países como Inglaterra ${ }^{8}$, Canadá 9 e EUA 9 , que desenvolvem estudos específicos com a população LGBT. A presença dessas pessoas no ambiente da rua, seja no Brasil ou no exterior, relaciona-se com a quebra de vínculos familiares devido à discriminação por ser LGBT ${ }^{5,6,9}$.

Apesar da existência de estudos anteriores descrevendo a presença de pessoas LGBT nas ruas, o censo da PSR do município de São Paulo, realizado em 2015, foi o primeiro trabalho que mensurou esse grupo, identificando que $8,9 \%$ da população se declara como

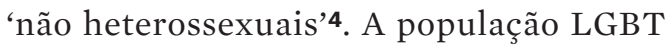
em situação de rua possui piores indicadores de saúde e apresenta maior dificuldade de acesso aos serviços de saúde, quando comparada com os heterossexuais ${ }^{4,10}$.

As discussões sobre gênero - definido como construções sociais, modos de ser e de agir desempenhados e reiterados pelas pessoas conforme sua condição e relações de poder presentes na sociedade - têm sido incorporadas no campo da saúde como importante determinante social ${ }^{11,12}$. Assim, categorias como identidade de gênero (identificação pessoal em relação ao gênero), expressão de gênero (forma como a pessoa apresenta-se e comporta-se socialmente) e orientação sexual (direcionamento afetivo-sexual da pessoa) passaram a compor pesquisas e políticas públicas de saúde, embora ainda apresentem debilidade na sua utilização na prática ${ }^{\mathbf{1 3}}$.

Neste trabalho, adota-se uma perspectiva butleriana ${ }^{12}$, sendo as identidades de gênero, as expressões de gênero, a orientação sexual e o sexo compreendidos como um efeito provisório de reiterações naturalizadas, que estão em constante construção no plano individual e social. Entretanto, apesar de seu caráter provisório, percebe-se que algumas dessas naturalizações ganham status de verdade no jogo social ${ }^{12}$.

Assim, a heteronormatividade - que prescreve a heterossexualidade como única condição normal e coerente - é uma dessas naturalizações que submete LGBT à condição de anormalidade ${ }^{\mathbf{1 4}}$. Esse condicionamento social à anormalidade é sustentado pelo que Bourdieu ${ }^{15}$ conceitua como violência simbólica, mecanismo pelo qual as desigualdades são naturalizadas e impostas de forma sutil nas relações sociais vigentes, legitimando processos de dominação e mantendo a ordem vigente. Assim, pessoas LGBT ficam em uma situação de maior vulnerabilidade a processos discriminatórios e violentos com efeitos diretos na saúde ${ }^{5}$.

Considerando que os fatores econômicos e socioculturais se relacionam com a distribuição da morbimortalidade nos grupos sociais, em que os menos favorecidos adoecem mais e de formas mais severas ${ }^{\mathbf{1 6}}$, percebe-se que a 
população LGBT em situação de rua é vulnerada de forma mais intensa pela intersecção de fatores discriminatórios. Sendo assim, esta passa por episódios discriminatórios diferentes daqueles sofridos por LGBT que não moram nas ruas e pela PSR que se encaixa no padrão heterossexual, constituindo-se como um grupo específico e invisibilizado pelas políticas públicas, profissionais de saúde e gestores do SUS.

Dessa forma, o presente trabalho objetivou compreender as implicações das identidades de gênero nas relações sociais e na saúde de pessoas LGBT em situação de rua de Florianópolis (SC).

\section{Material e métodos}

Trata-se de uma pesquisa qualitativa que compreende um conjunto de práticas que englobam os sentidos atribuídos pelos indivíduos às experiências e vivências e aos contextos relacionais em que estão inseridos ${ }^{17}$; ou seja, os sentidos atribuídos pelas pessoas LGBT em situação de rua acerca de suas vivências cotidianas e na relação com os serviços de saúde.

A pesquisa foi desenvolvida entre novembro de 2017 e abril de 2018 nas ruas do Centro, em Florianópolis (SC). Em 2017, a PSR do município possuía 938 pessoas, sendo desconhecido o número de LGBT ${ }^{19}$. A PSR concentra-se no bairro Centro e arredores, onde estão grande parte dos comércios, serviços e as principais instituições de apoio à PSR ${ }^{19}$.

Frequentou-se diariamente e em diferentes horários os espaços ocupados pela PSR. No primeiro momento, buscou-se adentrar ao campo e construir vínculos, devido à dificuldade de acesso aos diálogos e vivências. Em seguida, foram identificadas as pessoas LGBT em situação de rua para a realização das entrevistas. Durante todas as abordagens, a postura de escuta e respeito, rompendo com a invisibilização e estigmatização, foi fundamental para produção de vínculos.

Para coleta de informações, foram utilizadas entrevistas individuais semiestruturadas ${ }^{20} \mathrm{e}$ observação no cotidiano ${ }^{\mathbf{1 8}}$. A opção pela entrevista individual justificou-se pelo interesse em aprofundar a conversa em determinadas trajetórias e temas ${ }^{18}$. Realizou-se o convite para as entrevistas por amostragem de conveniência, sem a pretensão de representatividade numérica ${ }^{20}$. Foram convidadas todas as pessoas LGBT em situação de rua identificadas. O Termo de Consentimento Livre e Esclarecido (TCLE) foi lido e disponibilizado, porém, não foi considerado importante, sendo dispensada a assinatura e o recebimento.

As entrevistas foram realizadas de forma dialogada em locais improvisados do espaço público da cidade. Para direcionar a conversa, utilizaram-se os seguintes tópicos: motivos que o levou para a rua; processo da saída de casa e fixação na rua; motivos que o mantém na rua; cuidados em saúde; e relação com os serviços de saúde. As entrevistas não foram gravadas por solicitação dos entrevistados.

O registro das informações provenientes do campo de pesquisa foi realizado em diário de campo. Nele, foram anotadas as percepções do pesquisador, partes de relatos e falas das conversas informais e entrevistas. Os registros provenientes da pesquisa foram digitados para análise. Realizou-se a codificação dos participantes, mediante a identidade de gênero (Homem - H e Mulher - M) e orientação sexual referida (Gay - G, Lésbica - L, Bissexual - B e Sem Orientação Sexual Definida - SOD) para apresentação dos resultados.

A análise foi realizada por meio de imersão no material coletado, produção de categorias e articulação com os referenciais teóricos ${ }^{20}$. Após a leitura exaustiva dos registros, foram produzidas cinco categorias, conforme relatos e observações das pessoas LGBT. Por fim, realizou-se a reflexão acerca das categorias produzidas, debatendo-as com a literatura de gênero, PSR e saúde coletiva.

Durante a pesquisa, foi realizada articulação com a Rede de Atenção à Saúde devido à demanda específica de um dos participantes. Após a conclusão do trabalho, as informações produzidas foram utilizadas 
em atividades com instituições de apoio às PSR do município.

O presente estudo foi submetido e aprovado, sob o protocolo ${ }^{\circ} 104963 / 2015$, pelo Comitê de Ética em Pesquisa com Seres Humanos da Universidade Federal de Santa Catarina, conforme a Resolução CNS no 466/12.

\section{Resultados}

Foram entrevistadas 6 LGBT em situação de rua, sendo 2 homens (1 gay e 1 bissexual) e 4 mulheres (1 lésbica, 2 bissexuais, 1 sem orientação sexual definida). Em relação à raça, 4 identificaram-se como brancos, e 2, como negros. A idade dos participantes variou de 18 anos a 44 anos, e o tempo de rua foi de 8 meses a 12 anos. Excetuando-se uma das participantes, que utilizava instituição de apoio para pernoite, todos dormiam em logradouros públicos.

Em relação às atividades desenvolvidas para o sustento, um deles faz a leitura de cartas de tarot, e outro, confecção de objetos de arte. Os demais sustentam-se, exclusivamente, de donativos recebidos de instituições públicas, grupos organizados da sociedade civil e pela mendicância.

As cinco categorias construídas na análise são: processo de ida para a rua; discriminação contra LGBT no ambiente da rua; desvio do foco de violência; relação com os serviços de saúde; processo de cuidado em saúde na rua.

\section{Processo de ida para a rua}

Entre os homens, gay e bissexual, o fato de ser LGBT não teve ligação direta com a quebra de vínculo familiar e ida para a rua. Nessas situações, havia aceitação da orientação sexual por parte da família; entretanto, a necessidade de viver novas experiências, o sentimento de limitação em morar entre casa e seguir rotinas foram os principais motivadores.

Ele resolveu morar na rua porque sentia que morando numa casa estaria limitado. Na rua teria novas experiências e poderia ajudar as pessoas, com o tarot, que é para ele uma maneira de 'mostrar o caminho' para os outros. (Relato sobre HG01).

...ele falou que foi porque já tinha essa vontade, havia saído de casa há um tempo e que a quebra de vínculo não teve relação com o fato de ser LGBT. (Relato sobre HBO1).

Essa característica, todavia, não correspondeu às narrativas das mulheres. Essas relataram que ser LGBT foi a motivação principal dos conflitos familiares, relacionados com o conservadorismo e crenças religiosas da família que não aceitavam nada fora do padrão heteronormativo. Nessas desvinculações forçadas, situações como discriminação racial, dificuldade financeira, institucionalização forçada, violências por serem LGBT e por portar o Vírus da Imunodeficiência Humana (HIV) foram determinantes na ida para as ruas.

Ela e a mãe tinham um relacionamento conturbado, a mãe tinha medo que ela 'virasse lésbica', isso foi resolvido - para a mãe - quando, aos 17 anos, engravidou. Tinha um péssimo relacionamento com o padrasto, um homem evangélico, muito racista e homofóbico, uma das principais razões da ida para a rua. (Relato sobre MB01).

Ela estudou numa escola da qual foi expulsa por beijar uma menina atrás do ginásio e antes havia sido impedida de usar o banheiro por ser portadora de HIV. Começou a sofrer bullying no orfanato e saiu de lá para trabalhar no corre no morro (trabalho com o tráfico de drogas nas comunidades de Florianópolis, localizadas nos morros da cidade). Depois disso foi pra rua. (Relato sobre ML01).

Constatou-se uma dicotomia nas motivações de ida para a rua: por opção e por imposição. Entre os participantes deste estudo, percebeu-se que o fator 'opção' foi uma característica dos homens LGBT, e 'imposição', as das mulheres LGBT. 


\section{Discriminação contra LGBT no am- biente da rua}

Acerca das vivências nas ruas, percebeu-se a presença constante da discriminação por ser LGBT, sendo que essas atitudes discriminatórias ocorrem de maneira mais escrachada nesse espaço. Entretanto, embora seja possível constatar um relacionamento de solidariedade entre os LGBT e não LGBT na rua, as piadas com conteúdo discriminatório, que, inevitavelmente, ofendem aqueles que se identificam LGBT, são mantidas.

Dois rapazes faziam muitas piadas homofóbicas e gerou uma briga. Ele falou 'isso não machuca somente as pessoas de quem vocês estão falando, isso me machuca também'. (Relato sobre HG01).

Um rapaz que estava junto começou a apontar para seus amigos, todos heterossexuais, e dizer 'esse é LGBT', em tom de piada. (Relato de observação).

Esse tratamento vexatório foi vivenciado durante a coleta de campo quando apresentavam a temática da pesquisa. Eram constantes as ironias do tipo: "este é $L G B T$, aquele é $L G B T$ ”, apontando para pessoas não LGBT, com o intuito de ofendê-las ao tratá-las dessa forma; esse tipo de atitude gerou revolta por parte dos moradores de rua LGBT.

Nesse sentido, constatou-se que a rua é um espaço mais permissível para declarações discriminatórias para pessoas LGBT, principalmente por homens heterossexuais, que compõem grande parte da PSR. Não se verifica o desconforto em ofender as pessoas LGBT, o que faz com que palavras como 'bicha' e ‘viado' sejam constantemente utilizadas de forma pejorativa. Tal cenário fez com que os interlocutores solicitassem que as entrevistas e conversas ocorressem em locais isolados, para que eles se sentissem mais seguros.

Além da violência verbal direcionada às pessoas LGBT, as mulheres lésbicas e bissexuais são coagidas e violentadas pela não aceitação de sua orientação sexual. São comuns propostas de homens para troca de drogas e alimentos por sexo, mesmo sabendo da orientação sexual das mulheres, sendo que alguns persistem de forma violenta para obtenção das relações sexuais.

Ainda é estranho ser $L G B T$, as pessoas ainda fazem piada e não entendem muito bem. (Fala de MB01).

Existem homens, principalmente os mais velhos, que tentam trocar comida e drogas por sexo, não aceitam que ela goste de mulheres, e ela se incomoda com tais propostas. (Relato sobre MLO1).

Percebe-se que, apesar de a vida na rua representar, para alguns, um espaço de novas experiências e, para outros, uma forma de sair de ambientes violentos, as discriminações contra as identidades de gênero LGBT persistem. Entretanto, a configuração da vida na rua, com sua fluidez e indefinição geográfica, permite que essas pessoas se desviem e se afastem dessas relações discriminatórias.

\section{Desvio do foco da violência}

Verificou-se que, entre as pessoas LGBT em situação de rua, algumas características individuais serviam como estratégia de proteção. Dentre as características, destacam-se: modificações corporais, como piercings e tatuagens, incluindo tatuagens nos olhos; aspectos comportamentais/culturais, como a mescla de aspectos ciganos e hare krishna, trazendo um ar de mistério; e expressão de comportamento masculinizados com uso de top para apertar os seios, cabelos curtos e roupas masculinas.

Essas características são utilizadas como 'repelente' para outras pessoas em situação de rua, que, em geral, temem aproximar-se desses indivíduos; desse modo, previnem-se de processos violentos.

Ele lia cartas e utilizava roupas que mesclavam 
aspectos da cultura cigana e da cultura hare krishna, criando em torno de si uma figura mística, que gerava temor por parte da PSR, mantendo-o mais afastado dos demais. (Relato sobre HG01).

Ela tinha 4 piercings na glabela, um no queixo e um em cada bochecha, olhos tatuados, três tatuagens no rosto e a língua partida ao meio. Isso 'afastava os outros', ela me disse. (Relato sobre MBO2).

Outro motivo de desvio do foco das atitudes discriminatórias contra LGBT foi o fato de as pessoas serem negras. Estas são inicialmente estigmatizadas e violentadas por serem negras, sendo que isso, em alguns momentos, mascara o fato de serem LGBT. Entretanto, geralmente são acionados de forma interseccional, potencializado a discriminação sofrida.

Ela falou que antes de se identificar como homem, mulher ou LGBT, já sofria por se perceber como uma pessoa negra, que sofreu racismo desde que existiu. (Relato sobre MSOD01).

Quando virou moradora de rua; como mulher negra, sentia que os homens queriam aproveitar dela, da fama de 'boa de cama' que a mulher negra tem. (Relato sobre MSOD01).

Nota-se que esses desvios de foco, apesar de minimizarem a vulnerabilidade, não modificam o contexto em que vivem. Ou seja, continua-se a conviver com as violências em um meio discriminatório, adaptando-se a ele.

\section{O processo de cuidado em saúde}

Os problemas de saúde na PSR acionam e potencializam a solidariedade entre o grupo. Percebeu-se que a dificuldade de acesso à assistência de profissionais de saúde faz com que eles desenvolvam um cuidado de saúde entre si, com estratégias próprias da rua.

Quando alguém está doente, os demais cuidam da pessoa, procuram comida, mangueiam (contam histórias verídicas ou não para obter dinheiro, ou pedem ajuda financeira diretamente para pessoas que não moram nas ruas) por ela, compram medicamentos e fazem chás. (Relato sobre HB01).

Nesse sentido, os participantes relatam que as discriminações que sofrem como LGBT não acontecem nesses momentos; sendo que as mesmas pessoas que fazem piadas e violentam em alguns momentos, quando há um problema de saúde, cuidam e ajudam na recuperação.

Ele percebe na rua um ambiente de maior empatia e de ajuda, quem tem cigarro, bebida, comida sempre divide e isso se maximiza na situação de doença. (Relato sobre HG01).

Entretanto, a formação de grupos entre a PSR faz com que esse cuidado, no caso dos LGBT, seja majoritariamente dado pelas outras pessoas LGBT em situação de rua.

Ela falou que na rua já teve hepatite, ficou mal e que seus amigos próximos cuidaram dela, deram comida e manguearam para poder cuidar dela. (Relato sobre MB01).

Devido à precariedade de acesso a serviços de saúde, quando há um momento de vulneração, principalmente relacionado com a doença, essa é mais relevante que os preconceitos existentes; e, nesses momentos, todos se cuidam entre si. Sendo os grupos mais próximos, tornam-se cuidadores integrais.

\section{A relação com os serviços de saúde}

A relação de LGBT em situação de rua com os serviços de saúde é dificultada pelas más experiências com profissionais. Em geral, preferem o cuidado na rua evitando o cuidado profissional, principalmente em casos menos graves.

Espero estar morrendo, não gosto dessas coisas, passo longe de profissional de saúde. (Fala de HB01). 
Ela relatou que, como todos os médicos se preocupavam apenas com suas tatuagens e piercings, evitava procurar ajuda profissional até o último momento, a última vez que precisou de ajuda foi diretamente a emergência com intensa dor abdominal. (Relato sobre MB02).

Percebeu-se que o relacionamento negativo com os serviços e profissionais de saúde é justificado pelas abordagens inadequadas que experienciaram. Os profissionais de saúde, durante $o$ atendimento, mesmo quando não há necessidade, ressaltam questões de cunho preconceituoso sobre HIV, diversidade sexual e alterações corporais. Isso faz com que os problemas que os levaram aos serviços de saúde sejam ignorados.

A relação com serviços de saúde é péssima, todo profissional quer interná-la ou manda para o $\mathrm{Ne}$ reu (infectologia), ela espera outra abordagem que não se fale em internação no primeiro momento. (Relato sobre ML01).

Os médicos, ao atenderem ela, ignoram suas demandas e focam somente na tatuagem do seu olho, chegam jogando luz sem pedir licença. (Relato sobre MB02).

Sendo assim, essas barreiras e más experiências fazem com que as pessoas LGBT em situação de rua procurem por atendimento somente em casos extremos, preferindo o cuidado na rua, pelos companheiros de rua.

\section{Discussão}

O aumento da população LGBT em situação de rua, suas especificidades e demandas em saúde é um tema investigado de forma consistente no cenário internacional9,10,21. Nota-se que essa tendência de aumento é encarada como um problema social, fomentado pelas discriminações e iniquidades sociais, com reconhecido impacto na saúde9. Tais estudos costumam enfocar a população jovem, denominada homeless youths, que apresenta maior proporção de $\operatorname{LGBT}^{\mathbf{9}, 10,21}$.

No Brasil, esse é um tema pouco investigado $5,22,23$; e apesar da constatação do aumento da $\mathrm{PSR}^{7}$, há uma invisibilidade das pessoas LGBT em situação de rua nas discussões científicas, políticas públicas e serviços de saúde no cenário nacional. A emergência desse debate relaciona-se com o fortalecimento das discussões na sociedade e na academia sobre gênero e diversidade sexual, bem como o reconhecimento da categoria gênero como um determinante social de saúde ${ }^{\mathbf{4}, 24}$.

Acerca da ida para as ruas, o censo nacional6 aponta que os conflitos familiares foram motivadores em 29,1\% dos casos, superados pelo desemprego (29,8\%) e alcoolismo/drogas $(35,5 \%)$. Os rompimentos por conflitos familiares aparecem como principal fator para saída de casa de LGBT, principalmente jovens no cenário nacional de internacional ${ }^{\mathbf{1 0} 21}$.

Campos e Moretti-Pires ${ }^{5}$, estudando as trajetórias sociais de LGBT em situação de rua de Florianópolis (SC), observaram que violências verbais e físicas, como estupro corretivo, foram o estopim para saída de casa de gays e lésbicas. Santos ${ }^{25}$, em trabalho realizado na Ceilândia (DF) com travestis e transexuais em situação de rua, aponta que os conflitos familiares devido à identidade de gênero e orientação sexual foram a principal causa, entretanto, a religião e o empobrecimento também foram motivadores.

A ida para as ruas é relatada como uma 'opção forçada', diante do contexto de conflito vivenciado $^{10}$. Contudo, no presente trabalho, dois participantes relataram que foram para as ruas buscar novas experiências. Nesses casos, não havia conflitos familiares relacionados com fobias de gênero, apontando para novas configurações e estilo de vida em que a rua passa a não ser um endereço forçado, mas uma escolha pessoal.

A discriminação contra LGBT é uma constante na sociedade, sendo alvo de políticas e campanhas para mudança de comportamento, com vistas a erradicar qualquer violação pela identidade de gênero ou orientação sexual ${ }^{3}$. 
Sabe-se que os atos discriminatórios são oriundos do preconceito concretizado pelas fobias de gênero, ou seja, o medo ou ódio de pessoas LGBT que vivenciam uma experiência não heteronormativa ${ }^{14}$.

As piadas escrachadas contra LGBT e o uso dos termos 'bicha' e 'viado' para chacota no ambiente da rua são uma extensão dessa discriminação naturalizada na sociedade. Destaca-se um agravante nesse contexto, pois mais de $80 \%$ da PSR é formada por homens heterossexuais que tendem a desempenhar práticas de masculinidades violentas e heterocentradas ${ }^{26}$. Sabe-se que pessoas LGBT, em especial as mulheres, em situação de rua são mais propensas a sofrer violência e assédio sexual devido à percepção discriminatória e em função do machismo que submete as mulheres a situações de violência, resultando muitas vezes em mortes $\mathbf{2 7 , 2 8}$.

Percebe-se que a violência simbólica, operada na dominação masculina, aparece como um fenômeno social amplo e ramificado, reproduzido entre a PSR. Considerar a reiteração de uma suposta hierarquia social em que os homens heterossexuais exercem poder sobre os corpos femininos e de outras orientações sexuais é central para compreendermos as relações violentas nas ruas ${ }^{12,15}$. Assim, é necessário abordar a discriminação contra mulheres e LGBT nas políticas públicas e atividades de educação permanente para profissionais que atuam com a PSR para visibilizar a temática na atenção de saúde desse grupo.

Vista a violência vivenciada, os entrevistados apontaram alguns fatores que 'desviam o foco’ da discriminação por ser LGBT: modificações corporais, comportamentos específicos e cor da pele. Silveira, Michel e Silva ${ }^{29}$ apontam que a body modification é um fenômeno antigo, mas popularizou-se entre os jovens como uma forma de construção de identidade. No que tange ao 'desvio do foco', o estranhamento e o preconceito sobre a body modification parecem ser o mobilizador dessa proteção contra discriminações LGBT na rua.

Em relação aos comportamentos, deve-se separá-los em duas vertentes. A primeira trata-se de comportamentos não comuns para o contexto cultural, como o caso do hare krishna. Nessas situações, assim como na body modification, aciona-se um estranhamento e receio por parte dos demais moradores de rua, minimizado as aproximações e atitudes discriminatórias. A segunda trata-se de performatividade de gênero, mais especificamente práticas de masculinidades em mulheres ${ }^{25}$.

No contexto da rua, é possível identificar entre as mulheres a junção de vulnerabilidades relacionadas com gênero, sexualidade e cor da pele, sendo necessário um olhar interseccional. Ou seja, não se deve analisar as opressões sofridas de forma isolada, mas a partir da interação delas ${ }^{30}$.

Devido às práticas sexuais forçadas, é comum as mulheres apresentarem comportamentos compreendidos socialmente como masculinos para repelir os homens. Esse fenômeno não é exclusivo das mulheres LGBT, sendo percebido também em mulheres heterossexuais ${ }^{25}$. Tratando-se da cor da pele, apesar de o relato referir-se ao 'desvio de foco', nota-se uma intersecção mediante a erotização do corpo negro. Nesse sentido, apesar do aparente 'desvio' da violência, há um processo de vulnerabilidade ainda maior das pessoas LGBT negras nas ruas.

Lancellotti31, em estudo com mulheres com trajetórias de rua e encarceradas, faz um paralelo entre essas populações a partir de uma perspectiva interseccional. Trata-se de corpos negros, pobres e com baixa escolaridade que ocupam esses espaços. A PSR brasileira é composta por mais de $70 \%$ de pessoas negras, com baixa escolaridade e oriundas de classes sociais baixas ${ }^{\mathbf{4}, 6,19}$. Por outro lado, a precariedade das políticas públicas e a baixa qualidade dos serviços de saúde para essas populações transparecem uma estratégia necropolítica do Estado. Conforme Mbembe ${ }^{32}$, além do controle dos corpos, determinadas ações visam deixar morrer ou induzir a morte de determinados grupos sociais.

No campo da saúde, a Política Nacional de Atenção Integral à Saúde LGBT ${ }^{3}$ é um marco para equidade no SUS e na qualificação da 
saúde LGBT, todavia, apenas menciona as pessoas em situação de rua, não apresentando estratégias para atenção a esse grupo. Sena e Souto $^{33}$, ao analisar os avanços e desafios da política, apontam como principais entraves o processo transexualizador e ações específicas para mulheres lésbicas e bissexuais e para homens gays e bissexuais, sem mencionar as pessoas em situação de rua. Assim, apesar dos avanços com o SUS e suas bases sociais provenientes do Movimento da Reforma Sanitária, ainda é um desafio cuidar da saúde das pessoas LGBT em situação de rua.

Percebe-se grande insatisfação da PSR com os profissionais e serviços de saúde. O censo da PSR, realizado em 2008, já apontava que mais da metade da população havia passado por algum episódio de impedimento de acesso aos serviços de saúde ${ }^{6}$. Os LGBT nesse contexto apresentam piores indicadores de acesso quando comparados com os heterossexuais ${ }^{\mathbf{4}, 22}$. Constatou-se, neste estudo, que a exclusão dos LGBT dos serviços de saúde e o mal atendimento geraram um sentimento de revolta e insatisfação com o serviço ofertado.

Essas experiências negativas costumam causar sentimento de vergonha, pela condição de morar nas ruas, falta de condições de higiene e vestes precárias ${ }^{34}$. Tal sentimento encontra reforço em alguns setores específicos, como nos serviços de atendimento à saúde mental, pelo grande estigma existente, que rotula os usuários desses serviços como 'loucos'35. O que se percebe é que o desfecho final, para ambos os casos, é não acesso ao serviço.

Koopmans et al. ${ }^{36}$, em revisão integrativa sobre os cuidados à PSR, indicam que a "compreensão do outro", ou seja, as peculiaridades da vida em situação de rua, é um dos principais aspectos para qualificar a atenção dessa população. O acolhimento, a escuta qualificada e a construção de vínculos longitudinais são essenciais para evitar que eles cheguem somente por meio das urgências e emergências aos serviços de saúde.

Em função desse panorama, o cuidado de saúde é feito na rua sem a mediação de profissionais. Devido à exclusão social, tendem a negar a saúde enquanto um direito. Observase, assim, a solidariedade entre o grupo, minimizando discriminações contra LGBT em prol do cuidado. Vale e Vecchia ${ }^{37}$, em estudo realizado em uma Unidade de Pronto Atendimento (UPA), constatou que o uso das redes de apoio social pela PSR é a principal forma de cuidado em saúde. Faz-se automedicação por indicação dos colegas, utilizam conhecimentos e tratamentos da medicina popular para recuperação da saúde nas ruas.

Corroborando Johnson' ${ }^{9}$, os avanços sociais e legais voltados para as pessoas LGBT devem ser celebrados, entretanto não podem deixar de lado determinado grupos, como os LGBT em situação de rua. É preciso voltar as atenções para esses entraves, tanto como um problema social quanto como um desafio para o SUS.

\section{Considerações finais}

O aumento expressivo da PSR no Brasil assim como a invisibilização e a precariedade na saúde da população LGBT em situação de rua são desafios latentes para a sociedade e para a efetivação SUS enquanto um sistema universal, integral e equânime. Nesse sentido, buscou-se compreender as implicações das identidades de gênero nas relações sociais e saúde de LGBT em situação de rua de Florianópolis.

As discriminações contra LGBT no ambiente familiar foram motivações da ida para as ruas, entretanto, o desejo de novas experiências também apareceu como estopim. Nas ruas, constatou-se a presença de relações discriminatórias e violências perpetradas por outras pessoas em situação de rua, em especial, dos homens heterossexuais, envolvendo questões raciais e de sexualidade; sendo que aspectos comportamentais e físicos se apresentaram como forma de 'desvio de foco' para as violências sofridas.

A organização social heteronormativa direciona, de forma violenta, as trajetórias de vida e relações interpessoais nas ruas. As 
fobias de gênero permanecem como grande desafio para a cidadania LGBT, como impactos diretos na saúde. Assim, compreender a saúde em seu conceito amplo é central para qualificar os serviços do SUS e fomentar estratégias intersetoriais para saída das ruas. Para reorientar o modelo de atenção, deve-se considerar que a saúde depende de uma sociedade justa, equitativa e com respeito às diferenças.

Verificaram-se experiências negativas com os serviços de saúde, culminando na não procura pelos serviços, devido às más experiências pregressas com profissionais. Tal panorama faz com que se desenvolvam práticas solidárias para o cuidado em saúde, sendo que, nesses momentos, as discriminações contra LGBT entre a PSR, em geral, cessam.

\section{Referências}

*Orcid (Open Researcher and Contributor ID).
Desse modo, a visibilização das pessoas LGBT em situação de rua passa pela compreensão e respeito das especificidades da vida nas ruas, principalmente no que tange às discriminações e às violências sofridas. Nesse sentido, deve-se retomar a noção de determinação social do processo saúde-doença, fundamento da Reforma Sanitária e do SUS, repensando a prática cotidiana a partir das necessidades dessa população.

\section{Colaboradores}

Campos DA (0000-0001-6914-1184)*, Cardoso HM (0000-0002-8953-6412)* e Moretti-Pires RO (0000-0002-6372-0000)* são responsáveis pela elaboração do manuscrito.
1. Paim JS. Reforma sanitária brasileira: contribuição para a compreensão e crítica. Rio de Janeiro: Fiocruz; 2008.

2. Brasil. Ministério da Saúde. Saúde da população em situação de rua: um direito humano. Brasília, DF: Ministério da Saúde; 2014.

Transexuais - LGBT. Brasília, DF: Ministério da Saúde; 2008.

4. Fundação Instituto de Pesquisa Econômicas. Caracterização Socioeconômica da População Adulta em Situação de Rua e Relatório Temático de Identificação das Necessidades desta População na Cidade de São Paulo. São Paulo: FIPE; 2015.

3. Brasil. Ministério da Saúde. Política Nacional de Saúde Integral de Lésbicas, Gays, Bissexuais, Travestis e
5. 
de gays e lésbicas moradores de rua de Florianópolis (SC), 2016. Revista Est. Fem. 2018; 26(2):e45995.

6. Brasil. Ministério do Desenvolvimento Social. Pesquisa Nacional sobre a População em Situação de Rua. Brasília, DF: Ministério do Desenvolvimento Social; 2008.

7. Natalino MAC. Estimativa da População em Situação de Rua no Brasil. Rio de Janeiro: Ipea; 2016.

8. Fitzpatrick S, Pawson H, Bramley G, et al. The homelessness monitor: England 2017. London: Crisis Head Office; 2017.

9. Johnson RG. Public administration's ethical dilemma: Homeless LGBT youth in the twenty-first century. Journal Public Integrity. 2018; 20:539-541.

10. Keuroghlian AS, Shtasel D, Bassuk EL. Out on the street: a public health and policy agenda for lesbian, gay, bisexual, and transgender youth who are homeless. American Journal of Orthopsychiatry. 2014; 84(1):66-72.

11. Scott JW. Género: ¿ Todavía una categoría útil para el análisis? La manzana de la discórdia. 2011; 6(1):95101.

12. Butler J. Problemas de gênero: feminismo e subversão da identidade. Abingdon: Routledge; 2003.

13. Brasil. Ministério Público Federal. O Ministério Público e a Igualdade de Direitos para LGBTI: Conceitos e Legislação. Brasília, DF: MPF; 2017.

14. Warner M. Fear of a queer planet: Queer politics and social theory. Minnesota: University of Minnesota Press; 1993.

15. Bourdieu P. A dominação masculina. Rio de Janeiro: Bertrand Brasil; 2010.

16. Nogueira RP. Determinação social da saúde e reforma sanitária. Rio de Janeiro: Cebes; 2010.
17. Bosi MLM, Mercado FJ. Pesquisa qualitativa de serviços de saúde. Petrópolis: Vozes; 2007.

18. Aragaki SS, Lima MLC, Pereira CCP, et al. Entrevistas: negociando sentidos e coproduzindo versões de realidade. In: Spink MJ, editor. Escritos de Educação. Rio de Janeiro: Centro Edelstein de Pesquisas Sociais; 2014. p. 57-72.

19. Instituto Comunitário Grande Florianópolis. Diagnóstico Social Participativo da População em Situação de Rua na Grande Florianópolis. Florianópolis: ICOM; 2017.

20. Minayo MCS. O desafio do conhecimento: Pesquisa Qualitativa em Saúde. São Paulo: Hucitec; 2007.

21. Hafeez H, Zeshan M, Tahir MA, et al. Health care disparities among lesbian, gay, bisexual, and transgender youth: a literature review. Cureus. 2017; 9(4); ell84.

22. Garcia MRV. Diversidade sexual, situação de rua, vivências nômades e contextos de vulnerabilidade ao HIV/AIDS. Temas em Psicologia. 2013; 21(3):10051019.

23. Machado RWG. População LGBT em Situação de Rua: Uma Realidade Emergente em Discussão. Revista EDUC. 2015.

24. Gomes R, Murta D, Facchini R, et al. Gênero, direitos sexuais e suas implicações na saúde. Ciênc. Saúde Colet. 2018; 23(6):1997-2006.

25. Santos TES. A visão do trabalho entre pessoas LGBT em situação de rua [monografia]. Brasília, DF: Universidade de Brasília; 2018. 41 p.

26. Pinheiro ZAC. Vidas infames: uma etnografia das masculinidades, identidades de gênero e sobrevivências de homens que moram nas ruas [tese]. Marília: Universidade Estadual Paulista "Júlio de Mesquita Filho"; 2018. 250 p. 
27. Whitbeck LB, Chen X, Hoyt DR, et al. Mental disorder, subsistence strategies, and victimization among gay, lesbian, and bisexual homeless and runaway adolescents. Journal of sex research. 2004; 41(4):329-342.

28. Sousa RF. Cultura do estupro: prática e incitação à violência sexual contra mulheres. Estudos Feministas. 2017; 25(1):9-29.

29. Silveira AA, Michel CB, Silva MRS. Discutindo as práticas do Body Modification e as possíveis produções das identidades jovens. TEXTURA. 2016; 18(37):2749.

30. Crenshaw K. Documento para o Encontro de Especialistas em Aspectos da Discriminação Racial Relativos ao Gênero. Est. Fem. 2002; 10(1):171-188.

31. Lancellotti HP. Mulheres, Rua e Prisão: uma Análise do Perfil de Mulheres com Trajetórias de Rua Custodiadas na Penitenciária Feminina do DF. In: Anais do $1^{\circ}$ Seminário de Antropologia da UFSCAR; 2012; São Carlos. São Paulo: UFSCAR; 2012. p. 625-635.

32. Mbembe A. Necropolitics. In: Morton S, Bygrave S, editores. Foucault in an Age of Terror. London: Palgrave Macmillan; 2008. p. 152-182.

33. Sena AGN, Souto KMB. Avanços e desafios na im- plementação da Política Nacional de Saúde Integral LGBT. Tempus. 2017; 11(1):09-28.

34. Rodrigues JS, Lima AF, Holanda RB. Identidade, Drogas e Saúde Mental: Narrativas de Pessoas em Situação de Rua. Psicologia: Ciência e Profissão. 2018; 38(3):424-436.

35. Gomes CLT. O Direito à Saúde e a População em Situação de Rua: Análise da Experiência da Equipe de Consultório na Rua do Município de São Luís [monografia]. São Luís: Universidade Federal do Maranhão; 2017. 76 p.

36. Koopmans FF, Daher DV, Acioli S, et al. O viver na rua: Revisão integrativa sobre cuidados a moradores de rua. Rev. Bras. Enferm. 2019 [acesso em 2020 fev 20]; 72(1):211-220. Disponível em: http://www. scielo.br/scielo.php?script=sci_arttext\&pid=S0034$-71672019000100211 \& \operatorname{lng}=$ pt\&nrm=iso\&tlng=pt.

37. Vale AR, Vecchia MD. "UPA é nós aqui mesmo": as redes de apoio social no cuidado à saúde da população em situação de rua em um município de pequeno porte. Saúde e Sociedade. 2019; 28(1):222-234.

\footnotetext{
Recebido em 10/06/2019

Aprovado em 09/10/2019

Conflito de interesses: inexistente

Suporte financeiro: não houve
} 